\title{
Frederico Carlos Hoehne: viagem à Araucarilândia*
}

\section{Frederico Carlos Hoehne: a voyage to Araucaria's land}

\author{
José Luiz de Andrade FRANCO** \\ José Augusto DRUMMOND ${ }^{* * *}$
}

\begin{abstract}
RESUMO
O texto examina o pensamento do botânico brasileiro Frederico Carlos Hoehne (1882-1959) no que diz respeito à proteção da natureza e ao uso "racional" dos recursos naturais, usando como bases o seu relato sobre uma viagem de campo realizada em 1928 aos estados do Paraná e Santa Catarina e um texto posterior (de 1951) de sua autoria sobre reflorestamento e manutenção de habitats. Hoehne foi um pioneiro no tema entre os cientistas brasileiros do século XX e contribuiu para a emergência de uma consciência ambientalista no Brasil. A sua abordagem combinava argumentos científicos com apelos estéticos e difundia a percepção de que a natureza deveria desempenhar um papel importante na constituição da identidade nacional brasileira.

Palvaras-chave: conservação da natureza; Mata Attântica; desmatamento; identidade nacional; araucária; Paraná; Santa Catarina.
\end{abstract}

\begin{abstract}
The text is based on the travel notes written by the Brazilian botanist Frederico Carlos Hoehne (18821959) after a field trip made in 1928 to the Southern states of Paraná and Santa Catarina and on a later report of his (written in 1951) about reforestation and maintenance of habitats. It discusses his reflections and perspectives about the protection of nature and the "rational" use of natural resources. Hoehne was a pioneer among 20th-century Brazilian scientists in the subject of nature protection. His research and writings aided in the emergence of an early streak of environmental awareness in Brazil, in the 1930s and 1940s. His approach combined science and aesthetic arguments and was based on the assumption that nature should play an important role in the construction of the Brazilian national identity.

Key-words: nature conservation; Atlantic Forest (Brazil); deforestation; national identity; araucária; Paraná; Santa Catarina.
\end{abstract}

* Baseado parcialmente em FRANCO, 2002.

** Doutor em História pela Universidade de Brasília. Pesquisador associado do Centro de Desenvolvimento Sustentável da Universidade de Brasília. jlafranco@aol.com

**** Ph.D. em Recursos Naturais e Desenvolvimento. Professor adjunto do Centro de Desenvolvimento Sustentável da Universidade de Brasília. jaldrummond@uol.com.br 


\section{Introdução - objetivos, contexto e escopo}

O objetivo deste artigo é contribuir, por meio da análise da narrativa escrita por Frederico Carlos Hoehne sobre uma viagem que realizou em 1928 aos estados do Paraná e Santa Catarina e de um outro texto seu (de 1951) sobre a questão do reflorestamento e da manutenção de habitats, para a "redescoberta" do pensamento deste que foi um dos primeiros e ainda um dos maiores botânicos brasileiros.

$\mathrm{O}$ texto apresenta primeiro dados biográficos resumidos de Hoehne e, em seguida, explora as dimensões presentes em suas observações e reflexões acerca da natureza: a sua beleza, a importância de construir conhecimento científico a seu respeito e as possibilidades do seu uso "racional". É dada atenção especial às suas preocupações e propostas concernentes à conservação do patrimônio natural brasileiro. Por fim, é apresentada a preocupação de Hoehne em formular estratégias que vinculassem a valorização da natureza e da ciência à construção de um projeto de nação e à afirmação de uma identidade nacional brasileira.

Um contexto diferente para este texto é o esforço que vem sendo feito recentemente pelo Ministério do Meio Ambiente e pelo Ibama no sentido de criar unidades de conservação para proteger os últimos remanescentes das matas de araucárias, personagens principais do primeiro dos textos de Hoehne aqui analisados. Desta formação vegetal, que faz parte do grande bioma da Mata Atlântica, restam hoje em estado nativo ou pouco degradado menos de 3\% da sua área original. Estas matas são marcadas pela predominância da araucária (Araucaria angustifolia), árvore conhecida também como pinheiro-do-paraná, ou pinho-do-paraná, ou pinheiro-brasileiro, ou ainda curi. É importante acrescentar que o desmatamento dessas formações e a sua conversão em terras agrícolas e pecuárias são fenômenos relativamente recentes, ocorridos quase integralmente no século XX.

É verdade que uma parte importante dos remanescentes das matas de araucária está hoje protegida em três unidades de conservação criadas recentemente - os Parques Nacionais do Itajaí (2004) e das Araucárias (2005) e a Estação Ecológica da Mata Escura (2005). No entanto, estas medidas não autorizam muito otimismo quanto ao futuro dessas matas. Ao contrário, elas continuam a ser ameaçadas pelas estratégias de desenvolvimento ainda hegemônicas nas principais instâncias de decisão públicas e privadas locais. Isso fica evidente no caso da Usina Hidrelétrica de Barra Grande, sediada em Anita Garibaldi
(SC), a ser construída na divisa dos estados de Santa Catarina e Rio Grande do Sul. As águas barradas de rio Pelotas formarão um lago com cerca de $94 \mathrm{~km}^{2}$. Cerca de $5,5 \mathrm{~km}^{2}$ contínuos de matas e campos com araucárias estão sob ameaça de serem inundados por esse lago, em nome do imperativo da geração de energia (CASTELLA; BRITEZ, 2004; MEDEIROS et al. 2004; PROCHNOW, 2005).

Apesar de $5,5 \mathrm{~km}^{2}$ poderem parecer uma área pequena, é preciso lembrar que as matas de araucária, a formação florestal que há cerca de 75 anos mobilizou o trabalho e cativou a atenção do grande botânico que foi Hoehne, mesmo depois de reduzidas a menos de $3 \%$ de sua abrangência original, estão ameaçadas de perder mais esta parcela substancial.

\section{Dados biográficos de Hoehne}

Mineiro de Juiz de Fora, de ascendência alemã e origem humilde, Frederico Carlos Hoehne (1882-1959) não ultrapassou o nível secundário do ensino oficial. No entanto, movido por uma rígida autodisciplina, tornou-se um autodidata devotado à pesquisa nas áreas de botânica, biogeografia e ecologia. Ao estilo dos viajantes naturalistas do século XIX, percorreu todas as regiões do Brasil, coletou farto material para a organização de herbários e coleções científicas e contribuiu muito para a classificação da flora nativa, especialmente das orquídeas, o seu interesse principal. A sua vasta produção científica - mais de 500 artigos de divulgação, cerca de 50 conferências, uma centena de trabalhos e monografias científicas relacionados à botânica sistemática - alcançou reconhecimento nacional e internacional. Foi membro honorário da American Orchid Society, distinção conferida a poucos cientistas no mundo inteiro, e recebeu o título de doutor honoris causa pela Universidade de Göttingen, na Alemanha, em 1929 (FERRI, 1994; DEAN, 1996).

Hoehne iniciou a sua vida profissional em 1907, aos 25 anos de idade, como funcionário público - foi admitido como jardineiro-chefe do Museu Nacional do Rio de Janeiro. Em meados de 1908, fez a sua primeira grande excursão de campo, acompanhando, como botânico, a Comissão Rondon, no Mato Grosso e no Amazonas. Em 1910, retornou ao Mato Grosso, em companhia dos botânicos Hermano e Geraldo Kuhlmann, e em 1913, como integrante da Expedição Roosevelt-Rondon. Ao longo da sua vida profissional, viajou também por Minas Gerais, São Paulo, 
Paraná, Santa Catarina, Rio Grande do Sul e por todo o litoral brasileiro, tornando-se um profundo conhecedor da biogeografia do país. Ao todo foram 15 expedições científicas, nas quais ele e os seus colaboradores coletaram pelo menos 10.000 espécimes vegetais, correspondendo a pelo menos 4.000 espécies distintas, das quais cerca de 200 eram novas para a ciência. Hoehne descobriu e descreveu muitas dessas plantas. Dezenas de outras plantas da flora nativa brasileira, também novas para a ciência, foram batizadas com o seu nome, por iniciativa de colegas, assistentes e admiradores.

Foi em São Paulo, no entanto, que Hoehne se fixou profissionalmente e manteve uma atuação destacada no que diz respeito à proteção da natureza. A sua carreira esteve intimamente vinculada ao surgimento do Instituto de Botânica do Estado de São Paulo. De início, em 1917, implantou um horto de cultura e aclimatação de plantas medicinais, para o Serviço Sanitário, mas evoluiu para um projeto mais amplo, montando uma Seção de Botânica no Instituto Butantã. Mais tarde, em 1923, transferiu-se a Seção de Botânica para o Museu Paulista. Em 1928, houve mais uma mudança, agora para o Instituto Biológico de Defesa Agrícola e Animal, passando a denominar-se Seção de Botânica e Agronomia. A seção ganhou mais autonomia em 1938, quando se transformou em Departamento de Botânica, subordinado diretamente à Secretaria de Agricultura, Indústria e Comércio. Finalmente, em 1942, o Departamento se transformou no atual Instituto de Botânica, que se fixou no atual Jardim Botânico de São Paulo, fundado em 1928, por influência sua. Hoehne esteve sempre à frente dessas instituições. Foi responsável ainda pela gestão da Estação Biológica do Alto da Serra, exemplo pioneiro de espaço dedicado à conservação da natureza e à pesquisa científica. Trabalhou incansavelmente até 1952, quando, ao atingir a idade de 70 anos, recebeu aposentadoria compulsória. (FERRI, 1994; FRANCO; DRUMMOND, 2005; HOEHNE, 1943 a 1951; HOEHNE, 1937).

\section{Viagem à Araucarilândia: silvicultura e reservas naturais}

Em 1928, Hoehne fez uma viagem aos estados do Paraná e Santa Catarina, com o propósito maior de identificar cientificamente a madeira conhecida por imbuia (Ocotea porosa). Aproveitou esta viagem para estudar tam- bém a fitofisionomia da região, as suas orquídeas, as interações entre espécies variadas e as possibilidades de aproveitamento racional dos recursos naturais. Em 1930, publicou as suas conclusões em um livro intitulado Araucarilândia (HOEHNE, 1930), referência a esta região que o indígena chamava "sabiamente" de "Curitiba", o que significava aglomeração de pinheiros, para diferenciá-la de Pindorama, terra das palmeiras:

A “Araucária brasiliana” predominava; mas, associadas a ela, viviam outras árvores, outros arbustos e, muitas espécies de animais, que constituíam uma simbiose, ou sociedade mútua, interessantíssima, a que, com carradas de razões, se devia distinguir como uma biocenose singularíssima, diferente da "Pindorama"... (HOEHNE, 1930, p. 7)

Hoehne reconhecia, assim, uma sabedoria instintiva no indígena, que faltava aos colonizadores da terra. Os campos e as florestas do Paraná e de Santa Catarina estavam sendo devastados, o que ocorria também em quase todas as outras regiões do país. A situação era urgente e, no prólogo da Araucarilândia, as preocupações com a proteção da natureza aparecem de forma clara, expressando as motivações e disposições do autor:

Quem ama a pátria e se esforça por engrandecê-la não pode deixar de admirar sua natureza, nem deixar de protestar contra abusos cometidos em prejuízo dela.

Tais crimes avultam, aumentam de dia para dia, embora leis tenham sido criadas para coibi-los e apóstolos se levantem para combatê-los.

Quem se der ao trabalho de percorrer o interior do nosso país, para admirar suas riquezas naturais e avaliar suas possibilidades latentes, não poderá deixar de impressionar-se com a insensatez com que se pratica a devastação das belas e pujantes florestas, e a sem cerimônia com que se ateia fogo aos campos e cerrados, para vê-los destruídos por incêndios que duram semanas e até meses.

Os que compreendem o valor e a importância das dádivas que a natureza nos deparou nas selvas sombrias sabem que conviria termos mais parcimônia e mais previdência, mesmo na exploração das madeiras e no abater das matas para a formação de campos agrícolas.

Só os motejadores e egoístas podem sorrir a essas nossas observações e responder que as florestas e os cam- 
pos precisam desaparecer, para, em seu lugar, surgirem os campos de cultura, os prados para a pastagem do gado, as vilas e cidades, dos quais se colhem os cereais, a carne e a lã, e onde se vive e moureja comodamente, produzindo, pelas indústrias, pelo comércio e pelas artes. Não é para admirar que assim julguem, se ignoram o passado, sem se preocuparem com o futuro. Eles vivem para o presente e para o eu, somente.

(...)

A máxima parcimônia na destruição das florestas virgens recomenda um povo, porque nos denuncia o seu altruísmo e nos atesta sua previdência. (HOEHNE, 1930, p. 5)

O problema mais sério para Hoehne era a destruição de um patrimônio que não podia ser reconstruído pelos humanos, fruto de um arranjo natural que havia levado milhares de anos para se formar e sobre o qual a ciência tinha ainda muito que aprender. Além do mais, o valor deste patrimônio transcendia o uso econômico imediato; media-se fundamentalmente por um critério ético, que envolvia uma apreciação estética do mundo natural: como conjunto de seres interdependentes, constituintes de uma totalidade orgânica.

As selvas naturais e virgens encerram vidas e riquezas, cujo verdadeiro valor e importância real ainda se não podem avaliar devidamente. Protegê-las é defender um patrimônio que, uma vez perdido, jamais pode ser adquirido, quer pela força, quer pelo dinheiro. Salvaguardar as florestas, tanto quanto possível, é garantir maiores possibilidades e recursos para a agricultura, indústria e comércio; é edificar uma nação e assegurar vida aos seus filhos.

$\mathrm{O}$ direito de cada indivíduo acaba onde começa o de outro. Uma geração tem de respeitar o direito da advinda. A nenhuma assiste a faculdade de destruir ou reduzir as possibilidades de vida e gozo a aquela que a sucede.

O homem precisa compreender que é parte colaborante, elemento do conjunto de vidas sobre a face da terra e saber que, se se excede, deixando de respeitar o direito alheio, as conseqüências serão sentidas, não somente pelos oprimidos e prejudicados, mas mesmo por ele e por todo o conjunto.

(...)

Para estas árvores atingirem as dimensões que muitas delas têm, decênios foram necessários, muitos fatores contribuíram. Para prostrá-las em terra, trabalha um homem algumas horas ou um dia, e, desde então, modificadas ficam as condições, e em conseqüência disso, impossibilitada, para sempre, a reconstrução do estado primitivo. Quantas árvores tombam aos golpes do machado, quantas florestas desaparecem, no entanto, na voragem dos incêndios, sem que as madeiras que encerram venham ser aproveitadas, sem que o lenho produzido venha ter serventia, sem que o solo desnudado e carbonizado sirva mais que para plantar uma quarta de feijão ou de milho, para alimentar uma família durante alguns meses?! (HOEHNE, 1930, p. 5-6)

O colono, ao devastar os campos e as florestas, preparava a miséria futura. Faltava-lhe, segundo Hoehne, o discernimento adequado para a condução de uma vida em harmonia com o hábitat da região em que vivia. Isso conduzia, em pouco tempo, à necessidade de importar recursos, antes abundantes, de localidades mais distantes.

Alguém disse que o nosso caipira é semeador de taperas, fabricante de desertos e um inimigo das matas. Isso é exato. Além da instrução, falta-lhe o instinto que caracterizava o aborígine. De perdulário torna-se mau. O seu machado derruba e destrói anualmente, enquanto encontra, o quanto bastaria para dar fortuna a alguém mais ajuizado que soubesse aproveitá-lo.

Assim procederam e continuam agindo as vanguardas da nossa civilização, que denominamos pioneiros e desbravadores do sertão.

Onde a estrada de ferro chega, as florestas recuam. As vilas e as cidades que gozam dos seus benefícios, para o transporte das produções agrícolas e as comunicações, recebem as madeiras e a lenha de que carecem de pontos afastados, que não são servidos por ela, e têm de pagar, pelo seu transporte, sempre mais do que pelas mercadorias que exportam. (HOEHNE, 1930, p. 6)

A viagem de Hoehne ao Paraná e a Santa Catarina, em 1928, confirmava esta situação. Os governos deviam, alertava ele, dispensar mais atenção ao patrimônio natural. A legislação era um aspecto importante, mas, acima de tudo, era necessário cumpri-la e transformar o padrão de relacionamento do homem com o seu meio.

Isso que vemos passar por todo o Brasil verifica-se em todas as localidades que percorremos da Araucarilândia, 
onde penetra a locomotiva. As suas florestas desaparecem sem grandes benefícios para os seus habitantes. E dentro de alguns decênios só subsistirão as capoeiras, que logo serão sucedidas pelas taperas.

Urge que os governos oponham um dique à onda devastadora de madeiras, que ameaça transformar nossa terra em um deserto.

As leis votadas e condensadas nos códigos florestais do Governo Federal, dos Estados do Paraná e São Paulo, são magníficas, quanto ao seu teor, mas são letra morta diante do que observamos. (HOEHNE, 1930, p. 6)

Em Araucarilândia, Hoehne descreveu a flora nativa do Paraná e Santa Catarina, que o encantava pela sua diversidade de espécies: a vegetação do litoral, as florestas serranas, os campos, os aglomerados de araucária, imbuia e erva-mate. Não deixava de registrar as cenas de devastação, especialmente incêndios e derrubadas. Contudo, ao viajar pela estrada de ferro que liga Curitiba a Paranaguá, expressava a sua admiração pela plasticidade proporcionada pelo casamento daquele artefato humano com as belezas naturais da região:

Nunca poderá ser exagerado todo elogio e todo o louvor que se tecer a essas maravilhas do nosso país. A natureza é deslumbrante e a engenharia soube respeitála tanto quanto possível. Onde, porém, a depredou, ali ela se restabeleceu prontamente e de modo a impressionar-nos como virgem. Os viadutos que contornam a rocha abrupta e que contornam os vales ou grotas, onde as águas dos rios e ribeiros se precipitam tumultuosamente, causam medo e merecem respeito, porque denunciam arrojo e perícia extraordinários. As brumas e esguichos das águas pulverizadas levantam-se e regam a vegetação, que dos penhascos e das rochas abruptas pende, carregada de flores vistosas e atrativas. As delicadas frondes das samambaias e avencas balançam ao seu contato e deixam gotejar novamente as cristalinas lágrimas que pendem de cada segmento, fazendo-as rolar para o abismo, que se abre hiante e horrível, em meio de centenares de ramos de árvores que enchem os abruptos grotões.

Percorrendo essa estrada e observando tais paisagens, não se sabe a quem mais admirar, se ao engenho humano ou à arte divina. (HOEHNE, 1930, p. 34)

Hoehne acreditava na possibilidade de uma relação de parceria dos humanos com o mundo natural. Embora se encantasse com a beleza que, por si só, devia garantir o direito à existência de plantas e animais, a sua concepção de natureza sugeria um consórcio, no qual a preservação de faixas da floresta nativa propiciava habitats para pássaros e insetos que protegiam as culturas agrícolas de predadores e parasitas, além de um efeito benéfico sobre o clima e o regime das chuvas. As propostas de criação de áreas destinadas a reservas florestais foram uma constante na sua trajetória. Na volta do litoral para a cidade de Curitiba, desta vez seguindo de automóvel pela chamada Estrada da Graciosa, opinava que:

Se nos fosse permitido, sugeriríamos ao Estado ainda a criação de uma grande estação biológica, que abrangesse uma parte da zona litorânea e se estendesse encosta acima até ao terraço superior, com o fim de garantir a existência de todas as espécies vegetais e animais indígenas dessa zona.

As estações biológicas, como as reservas florestais, sempre foram e cada dia serão mais indispensáveis a um país, porque, com o seu auxílio, facilitamos imensamente o estudo e aplicação dos processos para o combate natural das pragas da agricultura e temos igualmente meios e elementos para pesquisar outros assuntos de biologia. (HOEHNE, 1930, p. 45)

Hoehne indignava-se com a ação dos madeireiros e das serrarias. Segundo ele, os bosques mistos de araucárias e imbuias deviam ter sido muito mais freqüentes, conforme se presumia do nome indígena da localidade, Curitiba. No entanto, as derrubadas e os incêndios que as seguiam transformavam estes bosques em capoeiras e taperas.

A proteção vergonhosa de que gozam os madeireiros dos dois Estados em questão (Paraná e Santa Catarina), com o taxamento da madeira estrangeira, que poderíamos importar por preço menor, sem essa taxa alfandegária, representa obra antipatriótica, ato que merece a condenação de quantos conheçam as condições locais e os processos por que são exploradas as florestas de pinheiro nessa parte do nosso país.

$\mathrm{O}$ abatimento dessas florestas deveria ser adiado o mais possível, porque não é agora, quando apenas a estrada de ferro penetra na região ocupada por elas, que mais necessárias se tornam as suas essências lenhosas. Com a população da região, aumentarão essas necessidades e então, naturalmente, mais cuidado se terá em poupar as 
matas, bem como em restaurá-las por processo natural, que consiste no afastamento completo dos incêndios, únicos fatores que determinam o desaparecimento das novas plantas que para tanto se tornam necessárias. (HOEHNE, 1930, p. 67)

Hoehne defendia a exploração racional dos bosques consorciados de pinheiro e imbuia. Para ele:

Houvesse um pouco de cuidado, não fossem os madeireiros tão gananciosos, as matas de "Pinheiros" nunca seriam destruídas e poderiam continuar a embelezar as regiões em que existem e fornecer, incessantemente, a madeira necessária para nosso abastecimento.

Para tanto, bastaria que se proibisse, terminantemente, o abatimento das árvores com menos de $70 \mathrm{~cm}$ de diâmetro e se evitassem, a todo o transe, os incêndios nas florestas em exploração. Porque dessa forma os "Pinheiros" maiores seriam suficientes para manter o ambiente necessário ao desenvolvimento dos mais novos, e produziriam bastante semente para que, nas clareiras abertas pelos cortes das mais vetustas, novos exemplares surgissem e se desenvolvessem.

Isso seria, assim, a manutenção e perpetuação das florestas nativas, pelo processo natural ou espontâneo, que não acarretaria outras despesas além das necessárias para o aceiramento... (HOEHNE, 1930, p. 108)

Mesmo onde as florestas de araucária já tivessem sido exterminadas, acrescentava Hoehne, era possível replantálas, desde que fossem convenientemente preparados os terrenos. Em 20 anos, os bosques estariam formados, em condições resistir a acidentes e incêndios, e prontos para serem explorados. Explicava as vantagens em plantar a imbuia e a erva-mate juntamente com a araucária, em um esboço de inovador programa de consorciamento de três espécies de árvores nativas, comercialmente valiosas e industrialmente úteis:

O crescimento da "Imbuia", como é conhecido, é muito mais lento do que o da Araucária, mas nas florestas mistas ela poderá formar o seu lenho, sem prejuízo, até mesmo com imensa vantagem para a última, porque é admirável para formar bosques em que os incêndios nada $\operatorname{arranjam}(. .$.

Outra planta que poderia e deveria ser associada ao " $\mathrm{Pi}$ nheiro" é o "Mate", que também concorreria para com- pensar o tempo de mora e a manutenção das florestas artificiais. (HOEHNE, 1930, p. 108)

Desse modo:

Santa Catarina, Paraná e São Paulo deveriam congregar-se e fazer dever seu a defesa da Gimnosperma que vimos descrevendo. Com ela e a "Imbuia" poderão formar florestas capazes de fornecer o essencial para as necessidades de madeira no próximo futuro. (HOEHNE, 1930, p. 108)

Os campos naturais - cerrados, cerradões, campos limpos, campos úmidos, etc. - do Paraná também deviam ser utilizados, pois poderiam servir como bons pastos para bovinos. Hoehne acreditava que a pecuária seria capaz de proporcionar recursos de maneira estável, sem comprometer a fauna e a flora da região, pois mais de $50 \%$ da superfície total do Estado compunha-se de campos. Além disso, propunha atividades econômicas variadas sustentáveis, de longo prazo, áreas de reserva de campos e matas e a arborização das cidades. Esperava que providências "enérgicas" fossem tomadas pelos governos estaduais e federal e que os cidadãos das áreas urbanas e rurais dos dois estados, por seu lado, viessem a se interessar pelas questões relacionadas à proteção do seu patrimônio natural.

\section{Reflorestamento e manutenção dos habitats}

No Relatório Anual do Instituto de Botânica, publicado em junho de 1951, Hoehne discutia, em artigo intitulado "Reflorestamento", um dos seus assuntos prediletos, já abordado no seu relato sobre campos e matas do Paraná e de Santa Catarina: a importância de conciliar a proteção da natureza com a exploração produtiva dos recursos da flora. Iniciava esclarecendo que "a fitofísionomia de um país deveria, entretanto, ser perpetuada como característica peculiar", o que protegeria a fauna e toda a biota (HOEHNE, 1951, p. 38). Ele sustentava os seus argumentos por meio da elaboração de um saber próprio do campo da biologia, conhecimento que, segundo ele, devia orientar a escolha de espécies adequadas ao cultivo do solo:

A flora e a fauna ajustam-se à topografia, clima e solo de uma região. As árvores e as ervas traduzem no seu 
aspecto e prioridades as influências exercidas sobre elas pelos fatores edafológicos e climatéricos, mas contribuem por seu turno para a manutenção dos mesmos fatores. Elas influem de modo considerável para a caracterização das diferentes zonas e regiões do globo e foi justamente por isso que os aborígines sempre apreciaram o processo de identificar cada localidade pelos seus fácies e não por aquilo que mais tarde pudesse ser criado. Os grandes botânicos: Prof. Dr. Adolfo Engler, Clements e muitos outros tiraram daí a idéia de organizarem mapas fitofisionômicos por meio dos quais se pode apreciar não apenas a diversidade do aspecto dos vegetais, mas tirar também conclusões práticas para o conhecimento do solo, seu valor em humo, teor de $\mathrm{pH}$, riqueza bacteriológica e micológica. Assim, a botânica pode prestar relevantes serviços à agricultura, orientando-a na escolha das espécies úteis a serem preferencialmente cultivadas em cada zona. (HOEHNE, 1951, p. 38)

Hoehne se preocupava com os processos - característicos do Brasil - de abertura de sucessivas fronteiras agrícolas, com base no uso inadvertido do machado e do fogo, e com a imprevidência predominante na exploração de recursos como madeira e lenha. Havia o perigo de que sobrasse, em um momento não muito longínquo, pouco da fitofisionomia original do país. Hoehne convocava os brasileiros a se engajarem em um esforço - que ele já julgava tardio - de preservação e de recomposição da flora e das físionomias nativas, caminho no qual avançamos pouco desde que ele escreveu essas palavras, há cerca de 80 anos:

... os Amigos da Flora Brasílica reúnam os que pugnam pelo Brasil brasílico e envidem esforços no sentido de preservar tudo que ainda existe e de reflorestar onde os terrenos desnudos existem, mas sem olvidarem que a vestimenta vegetal deve ser tecida com material aborígine, ter lavores de frondes das majestosas palmeiras, franças altaneiras dos gigantescos Jequitibás, ouro puro das flores dos fortíssimos Ipês e prata das Tabebuias paludícolas, como róseo maravilhoso das corolas das Sapucaieiras e o rubro intenso ou alaranjado das Eritrinas, para que verdadeira e não mascarada esta terra amada possa apresentar-se ao mundo... (HOEHNE, 1951, p. 38)

Tratava-se, portanto, de:
Antes de pensarmos no reflorestamento do Brasil,(...) primeiramente cogitar da conservação daquilo que ainda resta, evitando, por todos os meios e modos, o corte das matas nativas e livrando-as de incêndios e da exploração contraproducente. Isso seria a providência profilática recomendável para a solução do problema florestal e seria também iniciativa patriótica. (HOEHNE, 1951, p. 39)

O que se presenciava, no entanto, era bem diferente - um mecanismo de destruição de matas nativas em troca de promessas não-realizadas de plantio de florestas comerciais povoadas de espécies exóticas:

... Derrubadas, incêndios e explorações clandestinas em todos os recantos do nosso país. Os que querem aparecer na sociedade como cumpridores das leis altruístas chegam ao desplante de requererem licença para derrubarem florestas do patrimônio público, para em seu lugar plantarem essências exóticas que consideram melhor indicadas para o reflorestamento do nosso solo, porque, na sua opinião egoística, o indígena não possui as qualidades indispensáveis ao aumento do patrimônio nacional. Todavia, esses grandes patriotas de algibeiras insaciáveis não se lembrariam de demonstrar as suas asserções solicitando ao Estado os terrenos desnudos de sua vestimenta primitiva que se estendem ao lado das florestas naturais que pretendem transformar. Todos os que têm conseguido engazopar as autoridades com essas propostas figuram também no rol dos que prometem mas nunca cumprem. Aproveitadas a madeira e a lenha das matas que pretendem transformar, ficam novas taperas e seus promotores continuam tentando outras concessões, servindo-se sempre dos mesmos processos citados. (HOEHNE, 1951, p. 39)

Hoehne, que tinha viajado por quase todo o país, denunciava esses procedimentos que contribuíam para a devastação das matas e o mau aproveitamento do solo. Contudo, o problema não se limitava apenas aos especuladores, pois ele apontava que os agricultores de subsistência também punham abaixo e incendiavam as florestas, para plantar milho ou arroz, abandonando as terras poucas colheitas depois. Mesmo nos pontos mais afastados dos centros urbanos, a ameaça representada pelo machado e pelo fogo já era considerada alarmante, salvandose somente aquelas regiões mais ao norte do país, onde o 
clima, o terreno e a escassez da população ainda se constituíam em empecilhos à destruição de suas formações vegetais. Desse modo, argumentava:

Proceda-se ao reflorestamento com o florestamento, mas não se permita que, para isso, sejam sacrificadas as poucas matas naturais que ainda testemunham da nossa flora e que ainda continuam sendo o abrigo para a fauna indígena que não se pode manter nas florestas e bosques de essências lenhosas exóticas que aqui e acolá surgiram como excelentes recursos econômicos. (HOEHNE, 1951, p. 39)

O problema florestal assumia, segundo Hoehne, um duplo aspecto: econômico e científico. Para que houvesse uma política racional e previdente de uso das florestas, era importante que ambos os aspectos fossem considerados em conjunto. O que vinha acontecendo, no entanto, era que só se levavam em conta as vantagens econômicas imediatas, sem que se considerasse o lado científico. As florestas valiam para o madeireiro o número de metros cúbicos de madeira que fornecessem depois de derrubadas. Conforme o local em que estivesse a floresta, o lucro podia ser maior ou menor, sendo mesmo nulo nos locais de acesso mais difícil. Hoehne usava argumentos em defesa da flora nativa que ainda hoje soam modernos e inovadores:

Mas assim não pensam os biologistas que estudam e apreciam as florestas como fatores da biota, que se dedicam à reconstrução da História Natural. Para eles, a madeira e a lenha dessas florestas, embora sejam materiais dignos de serem estudados no que concerne à sua estrutura, resistência, peso específico e aplicações industriais correspondentes a essas características, são materiais equivalentes no seu valor biológico aos que o vulgo geralmente menospreza. Árvores, cipós, arbustos, ervas rasteiras ou eretas, terrestres ou dendrícolas, representam para o biologista objetos de estudos e pesquisas. Muitas vezes tem acontecido também que a ciência natural descobre princípios ativos numa trepadeira ou cipó, que o madeireiro considera incômodo para a sua indústria, e proporciona ao mundo o conhecimento de uma substância orgânica que remove dificuldades antes insuperáveis na agricultura. Outras vezes as pesquisas botânicas trazem para a indústria um látex que se transforma na base de um novo sistema de transportes terrestres. Mais comuns são, entretanto, as descobertas de recursos terapêuticos que se tornam imprescindíveis na medicina.

Tudo isso que ficou mencionado constitui o interesse científico das florestas. Muitas vezes os estudos realizados não apresentam resultados imediatos, mas mais cedo ou mais tarde se tornam sempre úteis à humanidade, como bastas vezes têm sido demonstrado. (HOEHNE, 1951, p. 40)

Assim, levar em conta o interesse científico era, ao mesmo tempo, uma forma de garantir interesses econômicos futuros. Proteger a diversidade da natureza no Brasil era fundamental para que ela fosse estudada e conhecida, inclusive com o propósito de otimizar o aproveitamento dos seus recursos. Hoehne argumentava que não era contra a introdução de essências exóticas, embora defendesse que os seus bosques, plantados com objetivos exclusivamente pecuniários, deviam ser estruturados em áreas onde não mais existissem matas nativas. De novo usando argumentos que podem parecer recentes ou contemporâneos, ele sustentava que reflorestar áreas desmatadas com essências lenhosas nacionais ou exóticas era utilíssimo:

... pois produzindo lenha e madeira suficientes para atender às necessidades sempre crescentes, não se precisará recorrer aos já escassos redutos das matas naturais. Fomentar a plantação de árvores que de fato utilidade apresentam merece elogios, não porém quando para o conseguir se condiciona a derrubada das matas naturais. Nesse caso, não haverá vantagens, mas tão somente desvantagens da tarefa realizada ou apenas projetada. (HOEHNE, 1951, p. 41)

Ainda assim, Hoehne preferia as essências nativas, com as quais podia reconstituir ambientes adequados para a fauna local. Argumentava que a silvicultura era uma atividade capaz de proporcionar não só lucros, mas também uma felicidade provinda da apreciação estética.

Rememoremos por um instante o que os bosques da Europa contribuíram para a literatura e quantos encantos e alegrias realmente aduzem aos seus proprietários. As árvores são escolhidas, plantadas e cuidadas, os seus troncos elevam-se e a ramagem se entrelaça e forma a verde abóbada. Alcatifa-se o solo de musgos e lindas 
ervas e logo ali aparecem os representantes da fauna ou são propositalmente soltos e cuidados pelos silvicultores. Os guardas florestais cuidam das árvores, retirando o que se torna supérfluo, mas zelam igualmente pelos animais de pêlo e penas e fiscalizam tudo para que nenhum dano possa ser aduzido ao conjunto biológico que assim se cria e conserva para renda e gozo do seu feliz proprietário... (HOEHNE, 1951, p. 43-44)

Essa silvicultura racional já vinha sendo praticada, segundo Hoehne, há séculos na Europa. Nos Estados Unidos, na Austrália e em algumas regiões da Ásia e da África, ela também já havia sido introduzida com sucesso. No Brasil:

Infelizmente, as espécies introduzidas, que constituem quase a totalidade das nossas florestas artificiais, são impróprias para formar ambiente para a nossa fauna, graças ao fato de que não possuem ramagem suficiente e própria para atrair e abrigar as aves e os mamíferos. Elas constituem árvores sem sombra e movimento. Proporcionam, todavia, boa renda a quem as planta e explora e a seu usufruto limita-se todo o prazer que lhe poderá advir da silvicultura. (HOEHNE, 1951, p. 44)

Bem diferentes em riqueza e diversidade faunística eram as nossas florestas nativas:

... No Paraná e em Santa Catarina ainda chegamos a conhecer algumas constituídas de Pinheiros, Imbuias e Erva-Mate. Assim, contaram-nos velhos paulistas, estendiam-se na região de Itu até a Serra de Botucatu e muitas outras localidades de São Paulo. À sua sombra poderia manter-se a caça de pêlo: queixadas, caititus, antas, pacas, cotias, etc., e podiam criar-se as aves que vivem no solo, tais como o são os mutuns, jaós, macucos, jacus, etc., bem como aquelas que vivem nas ramagens frutíferas: araras, papagaios, pombos, etc. A cavalo se podia correr nessas florestas sem chegar a ver o sol de sob a abóbada verde e ridente.

Tudo desapareceu, mas pode ser reconstituído se os afortunados tiverem senso estético para plantarem as árvores com arte e gosto. Escolhendo as essências lenhosas que existirem em cada região e plantando-as em promiscuidade, para que recíproca e mutuamente elas se auxiliem na disputa do ar e da luz, a natureza aduzirá o resto se o homem deixá-la agir e proteger na sua obra. (HOEHNE, 1951, p. 44)

A possibilidade de reflorestamento com árvores nativas, reconstituindo as feições fitogeográficas originais do país, entusiasmava Hoehne. A exploração econômica destes bosques, constituídos de espécies variadas de plantas, exigia, no entanto, que se respeitassem os prazos de crescimento e maturação de cada uma, que a espaços intercalados podiam recompensar vantajosamente os proprietários. Por isso:

Para a defesa biológica das florestas artificiais, recomendamos o emprego das essências lenhosas indígenas próprias da região e desaconselhamos o emprego de apenas uma espécie, porque, plantada em grande número de exemplares, fatalmente o bosque virá a sofrer com as pragas entomológicas e criptogâmicas(...) A natureza é a melhor mestra. Aquilo que ela reuniu numa floresta equilibra-se mutuamente e se dali se escolher o melhor para se reconstruírem florestas, o citado equilíbrio continuará existindo.

Para ambientar as aves e outros animais numa floresta artificial assim constituída, não devem ser esquecidas as árvores frutíferas. Muitas de entre elas fornecem excelentes madeiras e são de crescimento rápido... (HOEHNE, 1951, p. 44)

Outro ponto importante, no que diz respeito à fauna, é que para a sua livre reprodução eram necessárias áreas florestadas relativamente amplas. Isso poderia ser resolvido por meio do consórcio de fazendeiros vizinhos, a fim de formarem florestas contíguas, cuidando e explorando cada um a sua parte. Esse esquema antecipa as noções posteriores de reserva legal, de conectividade de áreas preservadas e de iniciativas particulares de preservação (como as atuais Reservas Particulares do Patrimônio Natural). Hoehne observava ainda que:

... a exploração da madeira e lenha a ser exercida nessas florestas mistas precisa ser levada a efeito com muito maior cuidado do que geralmente se necessita ter nas florestas uniformes constituídas de apenas uma espécie. Depois de retiradas as toras, a ramagem que não pode ser aproveitada para lenha deve ser picada e espalhada de modo tal que se decomponha o mais depressa possí- 
vel para não oferecer material de fácil combustão num eventual incêndio. $\mathrm{O}$ acesso do fogo às matas precisará ser evitado a todo o transe por meio de aceiros que também poderão funcionar como estradas ou caminhos. (HOEHNE, 1951, p. 44)

O reflorestamento se constituía em algo mais que simples atividade econômica. Era uma forma de criar laços mais fortes entre os humanos e a natureza, envolvendo uma experiência afetiva e a possibilidade de crescimento moral e espiritual. Hoehne defendia que:

Praticando o reflorestamento ou florestando solos desnudos, aprendamos que o útil pode e deve ser sempre ligado ao agradável. Esses dois proveitos cabem num saco se o senso estético e o patriotismo não estiverem totalmente sufocados pelo interesse egoísta e pelo excesso de amor ao dinheiro.

Propugnemos por um Brasil brasílico sem máscara. Um Brasil com as suas características peculiares. Uma pindorama e curitiba perpétuas, para que a brasilidade sobrepuje a xenofilia, sem transformar-se em xenofobia. Sim, reflorestemos onde possível, plantemos árvores úteis pelo seu lenho, úteis pelo seu aspecto e úteis pelos seus frutos e flores; escolhendo de entre o indígena o melhor, introduzindo do estrangeiro o que eventualmente possa ser aclimado e explorado vantajosamente sem prejuízo e nem menosprezo do que é nosso, por ser dádiva da nossa terra. Assim o reflorestamento tornar-seá prática louvável e patriótica. (HOEHNE, 1951, p. 45)

\section{Considerações finais}

Oriundo do interior de Minas Gerais - de área de Mata Atlântica devastada pelas fazendas, ferrovias e estradas da frente cafeicultora - e com uma formação de autodidata, Hoehne foi capaz de articular uma percepção muito sensível em relação à natureza e à sua diversidade, usando argumentos pragmáticos na defesa de sua conservação. Alertava, já em 1927, que:
Aquilo que a natureza criou, uma vez destruído, jamais poderá ser confeccionado artificialmente e (...) nas florestas e campos naturais ainda possuímos milhares e milhares de plantas e animais que não conhecemos mas que um dia talvez se tornem muito importantes e úteis para nós. (DEAN, 1996, p. 274)

Como vemos, Hoehne, ao refletir sobre a flora e a fauna, foi um cientista e cidadão que pensava no seu tempo e no tempo das gerações futuras de brasileiros. Os seus argumentos a favor do uso racional da flora nativa, dos reflorestamentos mistos e da preservação de faixas contínuas da floresta nativa para benefício da fauna podem hoje ser apresentados como relevantes e atuais em qualquer congresso sobre biodiversidade e meio ambiente. Hoehne apostava na possibilidade de que o Brasil corrigisse os seus rumos e de que, por meio de um projeto próprio, reconciliasse os humanos com a natureza. Atento às questões pertinentes ao contexto político-intelectual do seu tempo, procurou articular os problemas específicos da conservação da natureza com a questão da identidade nacional. O seu propósito era reunir conhecimento científico e sensibilidade estética a serviço da nação.

No que diz respeito a sua viagem à "Araucarilândia", vale lembrar que, àquela época, quando Hoehne chamava a atenção para a necessidade de uma exploração racional dos recursos florestais e para a criação de reservas de proteção das matas de araucária, essas matas ainda ocupavam mais de $50 \%$ de sua abrangência original. Essa relativa abundância possibilitava alternativas bastante mais "sustentáveis”. Hoje, a araucária e a imbuia, espécies arbóreas que foram o objeto principal da viagem de campo de Hoehne, correm perigo de extinção nas suas formas nativas. Mais do que isso, a flora e a fauna a elas associadas também estão ameaçadas (CASTELLA; BRITEZ, 2004; MEDEIROS et al., 2004; PROCHNOw, 2005). Esperamos que esta revisão do que Hoehne teve a dizer, há quase 80 anos, sobre as matas de araucárias valha para algo mais do que para alguém dizer, em um futuro não muito distante: "Enfim, não foi por falta de aviso". 


\section{REFERÊECIAS}

CASTELLA, Paulo Roberto; BRITEZ, Ricardo Miranda de (Orgs.). A floresta com araucária no Paraná. Brasília: MMA, 2004.

DEAN, Warren. A ferro e fogo: a história e a devastação da Mata Atlântica brasileira. São Paulo: Cia da Letras, 1996.

FERRI, Mário Guimarães. A botânica no Brasil. In: AZEVEDO, Fernando (Org.). As ciências no Brasil. v. 2. Rio de Janeiro: UFRJ, 1994.

FRANCO, José Luiz de Andrade. Proteção à natureza e identidade nacional: 1930-1940. Brasília, 2002. Tese (Doutorado em História) - Departamento de História, Universidade de Brasília.

FRANCO, José Luiz de Andrade; DRUMMOND, José Augusto. Frederico Carlos Hoehne: a atualidade de um pioneiro no campo da proteção à natureza no Brasil. Ambiente \& Sociedade, v. 8, n. 1, jan./jun. 2005.
HOEHNE, Frederico Carlos. Araucarilândia: observações gerais e contribuições ao estudo da flora e fitofisionomia do Brasil. São Paulo: Secretaria da Agricultura, Indústria e Comércio/Melhoramentos, 1930.

HOEHNE, Frederico Carlos. Relatório anual do Instituto de Botânica. São Paulo: Secretaria de Agricultura. 1943 a 1951.

HOEHNE, Frederico Carlos. Resenha histórica para a comemoração do vigésimo aniversário da Seção de Botânica e Agronomia anexa ao Instituto Biológico de São Paulo. São Paulo: Secretaria de Agricultura, Indústria e Comércio, 1937.

MEDEIROS, João de Deus; GONÇALVES, Marco Antônio; PROCHNOW, Miriam; SCHÄFFER, Wigold. Floresta com araucárias: um símbolo da Mata Atlântica a ser salvo da extinção. Rio do Sul: Apremavi, 2004.

PROCHNOW, Miriam (Org.). Barra Grande: a hidrelétrica que não viu a floresta. Rio do Sul: Apremavi, 2005. 